\title{
Prediction of Corner Columns' Load Capacity Using Composite Material Analogy
}

\author{
Ahsan Ali \\ Department of Civil Engineering \\ Quaid-e-Awam Universityof \\ Engineering, Science \& \\ Technology \\ Larkana, Pakistan \\ Pakistanahsanone@gmail.com
}

\author{
Zuhairuddin Soomro \\ Department of Civil Engineering \\ Quaid-e-Awam University of \\ Engineering, Science \& \\ Technology \\ Larkana, Pakistan \\ zuhairuddin@quest.edu.pk
}

\author{
Shahid Iqbal \\ Department of Civil Engineering \\ CECOS University \\ Peshawar, Pakistan \\ shahid.iqbalmce@gmail.com
}

\author{
Nadeem-ul-Karim Bhatti \\ Department of Civil Engineering \\ Quaid-e-Awam University College of Engineering, \\ Science \& Technology \\ Larkana, Pakistan \\ knadeem_b@yahoo.com
}

\author{
Ahmed Faraz Abro \\ Department of Civil Engineering \\ Quaid-e-Awam University of Engineering, Science \\ \& Technology \\ Larkana, Pakistan \\ a.faraz.abro@outlook.com
}

\begin{abstract}
There are numerous reasons for which concrete has become the most widely used construction material in buildings, one of them being its availability in different types, such as fiberreinforced, lightweight, high strength, conventional and selfcompacting concrete. This advantage is specially realized in highrise building construction, where common construction practice is to use concretes of different types or strength classes in slabs and columns. Columns in such structures are generally made from concrete which is higher in compressive strength than the one used in floors or slabs. This raises issue of selection of concrete strength that should be used for estimating column capacity. Current paper tries to address this issue by testing nine (09) sandwich column specimens under axial loading. The floor concrete portion of the sandwich column was made of normal strength concrete, whereas column portions from comparatively higher strength concrete. Test results show that aspect ratio $(\mathrm{h} / \mathrm{b})$ influences the effective concrete strength of such columns. A previously adopted methodology of composite material analogy with some modifications has been found to predict well the capacity of columns where variation in floor and concrete strength is significant.
\end{abstract}

Keywords-composite material analogy; sandwich columns; corner columns; axial loading

\section{INTRODUCTION}

There are many reasons for which concrete has become the most widely used building construction material. Concrete's ability to shape into any structural form, easy accessibility of its constituent materials and liberty of selecting among its various types, for example, fiber-reinforced, lightweight, high strength, conventional and self-compacting are few worth mentioning reasons. This choice of selection of different grades/types of concrete favors its application also in high-rise building construction. Concrete compressive strength used in construction has been increasing over the years and strengths up to $20 \mathrm{ksi}(138 \mathrm{MPa})$ and more have been used in the industry, especially in columns of high-rise buildings [1]. The use of high strength concrete column sections along the height, with higher-strength concrete placed in lower stories, results in additional savings associated with repetitive use of formwork. Compared to columns, high strength concrete is not required in floor/slab region of a framed structure. Also, economy and space requirements in high-rise building construction force designers to select concretes of different types/strength classes for slabs and columns. In such a state, presence of two different grades of concrete in slab-column region raises issue of selection of concrete strength $f_{c}^{\prime}$ to be used in (2) for estimating column capacity. ACI-318 [2] addresses the issue of variation in strengths of column and floor concretes in its section 10.12, where it recommends no special measures as long as the ratio of column to floor concrete strength $f_{c c}^{\prime} / f_{c s}^{\prime}$ is limited to 1.4. Requirements of ACI are based on [3] and state:

$$
\begin{aligned}
& \text { When } \quad f_{c c}^{\prime} / f_{c s}^{\prime} \leq 1.4 \\
& \qquad \begin{array}{l}
f_{c e}^{\prime}=f_{c c}^{\prime} \text { (for interior, corner \& edge columns) } \\
\text { When } \quad f_{c c}^{\prime} / f_{c s}^{\prime}>1.4 \\
f_{c e}^{\prime}=f_{c s}^{\prime}
\end{array}
\end{aligned}
$$

The maximum concentric load carrying capacity of the column can be obtained by adding the contribution of the 
concrete, calculated by $\left(A_{g}-A_{s t}\right) 0.85 f_{c}^{\prime}$, and the contribution of the steel $\left(A_{s t} f_{y}\right)$. The value of $0.85 f_{c}^{\prime}$ instead of $f_{c}^{\prime}$ is used in the calculations. ACI recommends this value on the basis of 564 tests on columns carried out during 1927 to 1933 at Lehigh and Illinois universities [4]. The nominal concentric load capacity of a column $P_{o}$ can be expressed as:

$$
P_{o}=0.85 f_{c}^{\prime}\left(A_{g}-A_{s t}\right)+A_{s t} f_{y}
$$

Rearranging (2), effective strength of concrete $f_{c e}^{\prime}$ can be defined as

$$
f_{c e}^{\prime}=\frac{P_{o}-A_{s t} f_{y}}{0.85\left(A_{g}-A_{s t}\right)}
$$

In [3, 5-10], researchers tried to address this subject and proposed different expressions and solutions. Few of these studies are discussed here to justify the proposed solution presented later in the paper.

Author in [5] tested six specimens with aspect ratio $h / b$ of 0.7 to understand the load transfer mechanism of high strength concrete column through a layer of lower strength slab concrete and to determine the effects of confinement on behavior of slab concrete. Treating the specimens as composite materials, he used mechanics of materials approach for developing (3) to calculate the effective concrete strength.

$$
f_{c e}^{\prime}=2.0 \lambda_{G} \frac{f_{c c}^{\prime} f_{c s}^{\prime}}{f_{c c}^{\prime}+f_{c s}^{\prime}}
$$

where, $\lambda_{G}=0.9,1.0,1.25$ for corner, edge \& interior columns respectively. Authors in [11] proposed (4) for computing effective concrete strength of a sandwich column and concluded that current ACI provisions for $f_{c c}^{\prime} / f_{c s}^{\prime}>1.4$ are overly conservative for edge and corner columns. Their results were based on tests conducted on 54 sandwich column specimens.

$$
\begin{aligned}
& f_{c e}^{\prime}=f_{c s}^{\prime}+A\left(f_{c c}^{\prime}-f_{c s}^{\prime}\right) \\
& \text { where } A=\frac{1}{\left(0.4+2.66 \frac{h}{b}\right)} .
\end{aligned}
$$

Authors in [7] investigated the effects of aspect ratio $h / b$ and column rectangularity on the effective concrete strength $f_{c e}^{\prime}$ of high strength concrete corner columns intersected by weaker slabs. The aspect ratio varied from 0.3 to 1.14 with maximum $12600 \mathrm{psi}(87 \mathrm{MPa})$ concrete strength. They concluded that it would be inaccurate to not consider aspect ratio in estimating the effective compressive strength of joint. Using mechanics of material approach like [5], authors in [12] suggest (5), a design expression for prediction of interior column capacity. They are of the opinion that the composite material analogy can be effectively applied for the theoretical analysis of the problem associated with estimating column capacity. However, like [5], their suggested equation also does not acknowledge the effect of aspect ratio.

$$
\sqrt[3]{f_{c e}^{\prime}}=2.0 \lambda_{G} \frac{\sqrt[3]{f_{c c}^{\prime}} \times \sqrt[3]{f_{c s}^{\prime}}}{\sqrt[3]{f_{c c}^{\prime}}+\sqrt[3]{f_{c s}^{\prime}}}
$$

where $\lambda_{G}=1.07$.

All mentioned studies signify the importance of aspect ratio $h / b$ and composite material analogy approach. Expressions proposed by some researchers are based on this approach but are independent of aspect ratio, whereas expression proposed in[11] is based on regression analysis rather mechanics of material approach.

\section{EXPERIMENTALPROGRAM AND TEST SETUP}

The experimental program included the testing of nine sandwiched column specimens in direct compression, as these specimens adequately model the corner column slab joint [5, 7]. Specimens were divided into three groups A, B and C, having three specimens in each group, each group had different ratio of column to floor concrete strength. Specimens in each group had slab/floor layer of 4, 6 and 8 inches $(102,152$ and $203 \mathrm{~mm}$ ). Slab portions were sandwiched between two column ends made up of comparatively lower strength concrete than the one used in column ends. Specimen with 4 inch $(102 \mathrm{~mm})$ thick slab layer had aspect ratio $h / b$ of 0.67 - typical to that of flat plate floor system, whereas those with 6 inch $(152 \mathrm{~mm})$ and 8 inch $(203 \mathrm{~mm})$ thick layer developed an aspect ratio of 1 and 1.33 respectively. Figure 1 shows the rest of the features of specimens in all groups. All specimens were tested in axial compression in a $2000 \mathrm{kN}$ capacity compression testing machine. First, the test specimens were installed in the testing machine, centered carefully to avoid any flexural stresses resulting from accidental eccentricity. Strain gauges applied to main reinforcement in slab region to monitor their performance under load were connected to the data logger. Three cylinders cast from the column concrete and slab concrete batches were tested first to obtain the axial compressive strength. This was followed by compressive testing of sandwich column specimens. Before testing, elastic pads were placed between specimen and machine loading plates to avoid damage to column ends. The load was applied in increments of $50 \mathrm{kN}$. During the test, specimen behavior was carefully monitored, cracks were marked on their appearance along with load readings. Strain gauge readings were also recorded after each load increment. After specimen failure, the crushed concrete around the failure area was removed to observe the behavior of the reinforcement. A typical test setup is shown in Figure 2(a).

\section{TEST RESULTS}

Test results confirm the established behavior of axially loaded columns, specimens in current experimental work failed due to buckling of the longitudinal bars and crushing of slab concrete. The buckling of longitudinal bars and crushing of slab concrete (see Figure 2(b)) took place almost simultaneously and suddenly. Although, at the beginning, 
smaller cracks appeared in the column ends near loading plates of testing machine, however the cracks which were the main cause of failure appeared later in the floor concrete area and progressed vertically until after spalling of cover concrete. Specimens with higher aspect ratios $(h / b)$ failed at lower loads, suggesting that aspect ratio does influence the column capacity thus confirming the findings of previous studies [7, 10]. The test results for all specimens are presented in Table I.
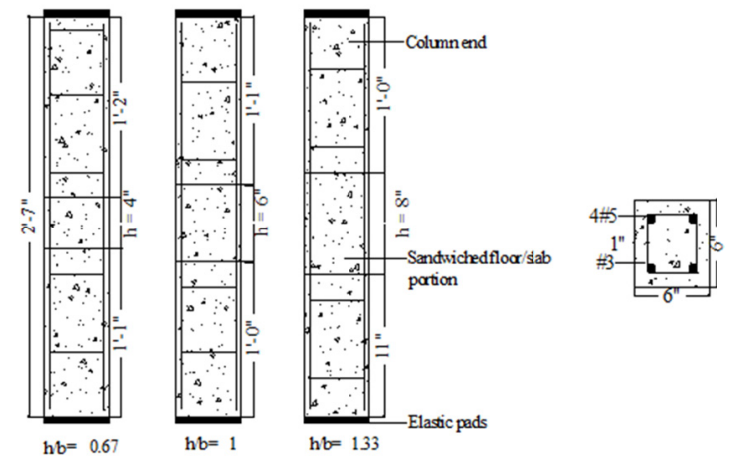

Fig. 1. Longitudinal\& cross sectional details of specimens

\section{COMPOSITE MATERIAL ANALOGY}

Proposed equation (3) in [5] is based on the principles of composite material. The same approach with some modifications is presented here. The basic principle or analogy is that the column with two different grades of concrete should behave like composite material made of two kinds of material. Composites are preferred for application as they result in favorable properties - fibrous composite is one typical example [13]. Figure 3(a) shows the representative volume element (RVE) having dimensions " $b$ " and simple states of stress in elementary mechanics of materials models. Comparison or similarities of RVE and a sandwich column (Figure 3(b)) with each other, along with equivalent homogenous material (Figure $3(\mathrm{c}))$ with effective transverse modulus of elasticity $\left(E_{y}\right)$ are highlighted in Figure 3. Acknowledging the significance of aspect ratio $(h / b)$ RVE is assigned dimensions of unit width "b". Unlike fibrous composite (RVE), where fibers are held or embedded by weaker matrix, weaker slabs are sandwiched between stronger column ends in this analogy. When the RVE or sandwich column is subjected to transverse normal stress $\sigma_{y}$ as shown in Figure 3(a), the response is governed by the effective transverse modulus $E_{y}$. Geometric compatibility requires that the total transverse composite displacement $\delta_{c y}$ must be equal to the sum of the corresponding transverse displacements in the fibers $\delta_{f y}$ and the matrix $\delta_{m y}$.

$$
\varepsilon_{c y} b=\varepsilon_{f y} L_{f}+\varepsilon_{m y} L_{m}
$$

Using definition of Hook's Law:

$$
\frac{f_{y}^{\prime}}{E_{y}}=\frac{f_{f y}^{\prime}}{E_{f y}} \times \frac{L_{f}}{b}+\frac{f_{m y}^{\prime}}{E_{m y}} \times \frac{L_{m y}}{b}
$$

$$
\varepsilon_{c y}=\varepsilon_{f y} \times \frac{L_{f}}{b}+\varepsilon_{m y} \times \frac{L_{m}}{b}
$$

If we assume that the stresses in the composite, matrix and fiber are all equal then above equation reduces to:

$$
\frac{1}{E_{y}}=\frac{L_{f}}{b \times E_{f y}}+\frac{L_{m y}}{b \times E_{m y}}
$$

From Figure 3 , it would seem that the assumption of equal stresses is valid because equilibrium requires that the forces must be equal for the series arrangement and both fiber and matrix blocks have equal areas normal to the y-direction. Simplifying and using sandwich column's notations, (6) becomes:

$$
E_{y}=\frac{b E_{s} E_{c c}}{h\left(E_{c c}-E_{s}\right)+E_{s} b}
$$

Modulus of elasticity is proportional to the square root of compressive strength. Here for the sake of simplicity and with little margin of error, it is taken proportional to compressive strength i.e. $E_{c} \alpha \sqrt{f_{c}^{\prime}}$ or $f_{c}^{\prime}$.

$$
f_{c e}^{\prime}=\frac{b f_{c c}^{\prime} f_{c s}^{\prime}}{h\left(f_{c c}^{\prime}-f_{c s}^{\prime}\right)+f_{c s}^{\prime} b} \Rightarrow f_{c e}^{\prime}=\frac{f_{c c}^{\prime} f_{c s}^{\prime}}{\frac{h}{b}\left(f_{c c}^{\prime}-f_{c s}^{\prime}\right)+f_{c s}^{\prime}}
$$

where $(h / b \leq 1)$. Condition of $h / b \leq 1$ is imposed to (7) for composite action to exist.

\section{RESULTS ANALYSIS}

It is believed that sandwich columns adequately model corner column slab joints. Therefore previous data of sandwich and corner columns have been used for analysis purposes by different researchers [3, 5-6, 11-12, 14]. For corner columns, ACI-318 recommends the use of puddle concrete or lower value of concrete strength, if the ratio of column to slab concrete strengths $f_{c c}^{\prime} / f_{c s}^{\prime}$ exceeds 1.4. If this ratio is less than or equal to 1.4 , no measures are suggested.

Results of effective concrete strength $f_{c e}^{\prime}$, following the ACI approach and the proposed one are presented in Table II. Figure 4 shows apparent concrete strength of current and previous samples plotted against the calculated values by ACI318 and proposed equation. The theoretical line at $45^{\circ}$ is also drawn to these plots along with the data points. From Table II with overall test to prediction ratio of 1.38 , the ACI equation is found to be too conservative, particularly for ratios of $f_{c c}^{\prime} / f_{c s}^{\prime}$ greater than 1.5. The effective strength calculated $f_{c e}^{\prime}$ using the newly proposed (7) has shown good correlation with the apparent strength $f_{c p}^{\prime}$ of tested samples. With an average test to predicted ration of 1.29 and standard deviation of 0.28 , the proposed design equation appears to be much safer than the existing code equation. 


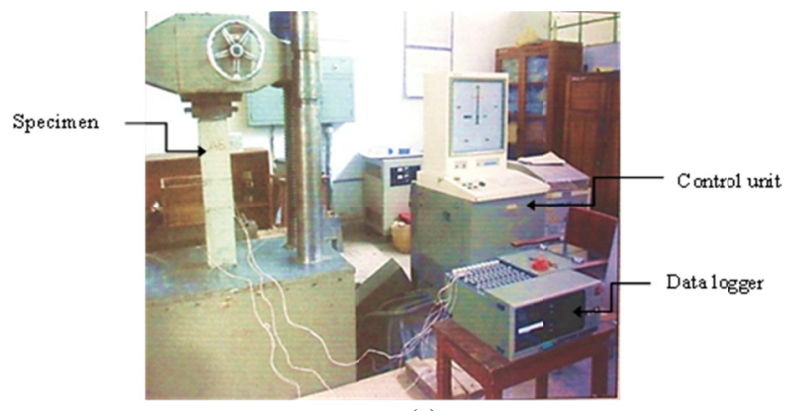

(a)

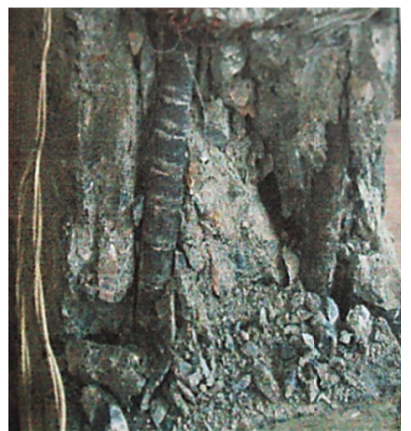

Fig. 2. (a) Test setup, (b) Failure of specimen in slab region

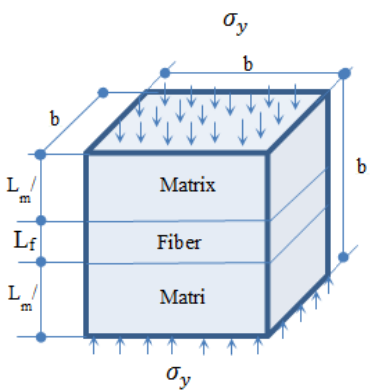

(a)

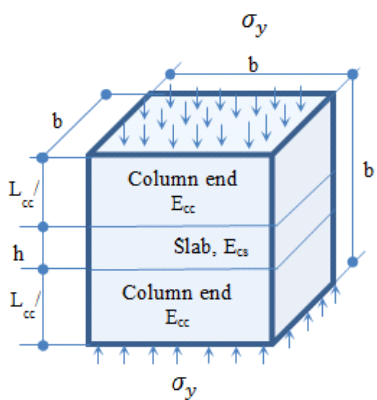

(b)

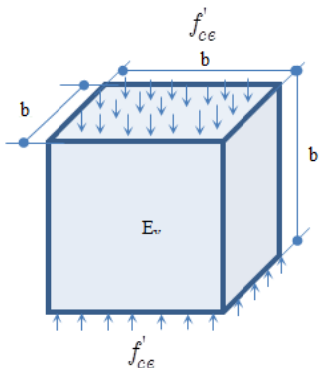

(c)

Fig. 3. (a) RVE (b) Sandwich column as composite material (c) Equivalent homogenous material

TABLE I. TEST RESULTS

\begin{tabular}{|c|c|c|c|c|c|c|c|c|c|c|}
\hline \multicolumn{2}{|c|}{ Specimen } & SCA- 4 & SCA-6 & SCA-8 & SCB-4 & SCB-6 & SCB-8 & SCC-4 & SCC-6 & SCC-8 \\
\hline \multirow{2}{*}{$\begin{array}{l}\text { Concrete } \\
\text { strength - } \\
\text { psi (MPa) }\end{array}$} & $\begin{array}{c}\text { Top } \\
\text { column }\end{array}$ & \multicolumn{3}{|c|}{6082 (41.93) } & \multicolumn{3}{|c|}{7754 (53.46) } & \multicolumn{3}{|c|}{$5342(36.84)$} \\
\hline & Slab & \multicolumn{3}{|c|}{2725 (18.79) } & \multicolumn{3}{|c|}{$2249(15.51)$} & \multicolumn{3}{|c|}{$2857(19.7)$} \\
\hline \multirow{2}{*}{$P_{t}$} & $\mathrm{lb}$ & 182700 & 177244 & 173692 & 194741 & 190545 & 187115 & 171163 & 165195 & 163865 \\
\hline & $\mathrm{kN}$ & 812.69 & 788.42 & 772.62 & 866.25 & 847.59 & 832.33 & 761.37 & 734.82 & 728.91 \\
\hline$f_{c p}^{\prime}$ & $\mathrm{MPa}$ & 25.27 & 24 & 23.17 & 28.08 & 27.10 & 26.3 & 22.59 & 21.19 & 20.88 \\
\hline \multicolumn{2}{|c|}{$f_{c c}^{\prime} / f_{c s}^{\prime}$} & \multicolumn{3}{|c|}{2.22} & \multicolumn{3}{|c|}{3.3} & \multicolumn{3}{|c|}{1.91} \\
\hline \multicolumn{2}{|c|}{$f_{c p}^{\prime} / f_{c s}^{\prime}$} & 1.34 & 1.28 & 1.23 & 1.81 & 1.75 & 1.696 & 1.15 & 1.08 & 1.06 \\
\hline \multicolumn{2}{|c|}{$h / b$} & 0.67 & 1 & 1.33 & 0.67 & 1 & 1.33 & 0.67 & 1 & 1.33 \\
\hline
\end{tabular}
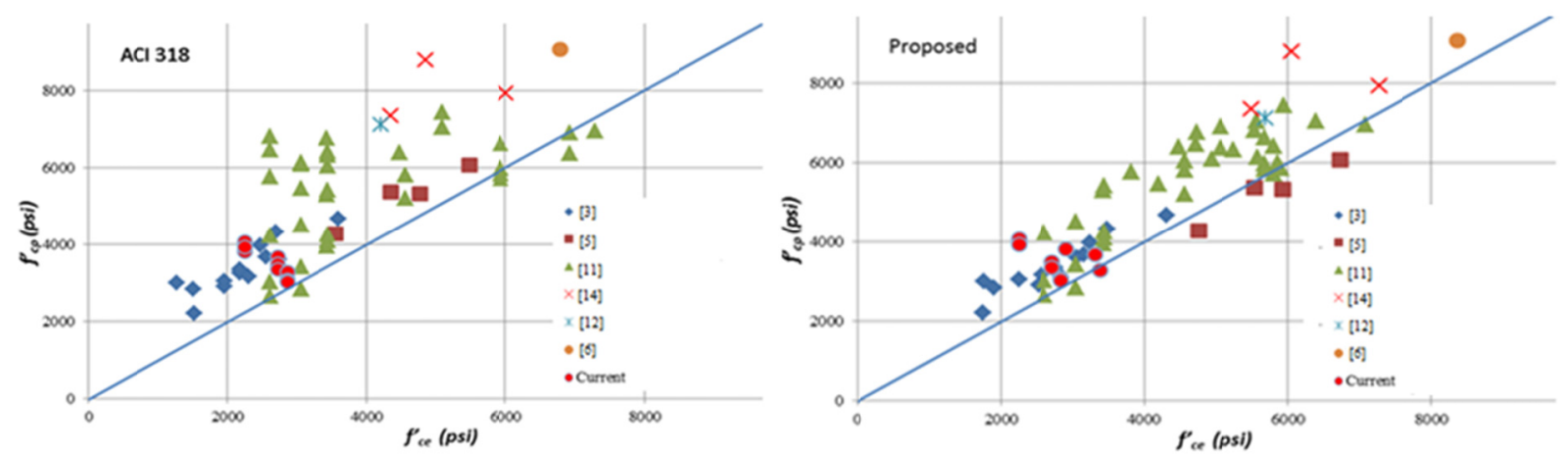

Fig. 4. Concrete strength graphs 
TABLE II. RATIO OF APPARENT TO EFFECTIVE CONCRETE STRENGTH

\begin{tabular}{|c|c|c|c|c|c|c|c|}
\hline \multirow{2}{*}{$\begin{array}{l}\text { Specimen } \\
\text { series }\end{array}$} & \multirow{2}{*}{$f_{c c}^{\prime}(\mathrm{psi})$} & \multirow[b]{2}{*}{$f_{c s}^{\prime}(\mathrm{psi})$} & \multirow{2}{*}{$f_{c p}^{\prime}(\mathrm{psi})$} & \multicolumn{2}{|c|}{ ACI 318-11 } & \multicolumn{2}{|c|}{ Proposed } \\
\hline & & & & $f_{c e}^{\prime}(\mathrm{psi})$ & $f_{c p}^{\prime} / f_{c e}^{\prime}$ & $f_{c e}^{\prime}(\mathrm{psi})$ & $f_{c p}^{\prime} / f_{c e}^{\prime}$ \\
\hline \multirow{3}{*}{$\mathbf{A}$} & 6051 & 2725 & 3666 & 2725 & 1.35 & 3329 & 1.10 \\
\hline & 6051 & 2725 & 3481 & 2725 & 1.28 & 2725 & 1.28 \\
\hline & 6051 & 2725 & 3361 & 2725 & 1.23 & 2725 & 1.23 \\
\hline \multirow{3}{*}{ B } & 7430 & 2249 & 3815 & 2249 & 1.70 & 2921 & 1.31 \\
\hline & 7430 & 2249 & 4073 & 2249 & 1.81 & 2249 & 1.81 \\
\hline & 7430 & 2249 & 3931 & 2249 & 1.75 & 2249 & 1.75 \\
\hline \multirow{3}{*}{$\mathbf{C}$} & 5449 & 2857 & 3275 & 2857 & 1.15 & 3389 & 0.97 \\
\hline & 5449 & 2857 & 3073 & 2857 & 1.08 & 2857 & 1.08 \\
\hline & 5449 & 2857 & 3028 & 2857 & 1.06 & 2857 & 1.06 \\
\hline \multicolumn{5}{|c|}{ Mean } & 1.38 & & 1.29 \\
\hline \multicolumn{5}{|c|}{ Standard deviation } & 0.28 & & 0.28 \\
\hline
\end{tabular}

\section{CONCLUSIONS}

Analysis and discussion of test results leads to the following conclusions:

- Specimens of all series confirm that the effective strength of an axially loaded column intervened by lower strength concrete floor is influenced by its aspect ratio $h / b$.

- As the aspect ratio increases, the effective strength of the joint decreases.

- The ACI 318, Section 10.12, provisions for $f_{c c}^{\prime} / f_{c s}^{\prime}>1.4$ are overly conservative for corner columns.

- Mechanics of composite materials can be used to predict the response of slab-column joints to axial loads. The proposed expression (7) can safely be used for predicting the effective concrete strength of axially loaded corner columns.

DENOTATION TABLE

\begin{tabular}{|c|l|c|l|}
\hline$A_{g}$ & $\begin{array}{l}\text { gross area of column cross } \\
\text { section }\end{array}$ & $L_{f}$ & length of fiber \\
\hline$A_{s t}$ & area of deformed bar & $L_{m}$ & length of matrix \\
\hline$b$ & least column dimension & $P_{o}$ & $\begin{array}{l}\text { nominal concentric } \\
\text { load capacity of } \\
\text { column }\end{array}$ \\
\hline$E_{c c}$ & $\begin{array}{l}\text { modulus of elasticity of } \\
\text { column concrete }\end{array}$ & $P_{t}$ & $\begin{array}{l}\text { axial test load applied } \\
\text { to column }\end{array}$ \\
\hline$E_{c s}$ & $\begin{array}{l}\text { modulus of elasticity of slab } \\
\text { concrete }\end{array}$ & $\rho$ & reinforcement ratio \\
\hline$E_{y}$ & $\begin{array}{l}\text { effective modulus of } \\
\text { elasticity in Y-axis direction }\end{array}$ & $\delta_{c y}$ & $\begin{array}{l}\text { axial displacement of } \\
\text { composite in Y- } \\
\text { direction }\end{array}$ \\
\hline$f_{c c}^{\prime}$ & $\begin{array}{l}\text { compressive strength of } \\
\text { column concrete }\end{array}$ & $\delta_{f y}$ & $\begin{array}{l}\text { axial displacement of } \\
\text { fiber in Y-direction }\end{array}$ \\
\hline$f_{c e}^{\prime}$ & $\begin{array}{l}\text { effective compressive } \\
\text { strength of column }\end{array}$ & $\delta_{m y}$ & $\begin{array}{l}\text { axial displacement of } \\
\text { matrix in Y-direction }\end{array}$ \\
\hline$f_{c p}^{\prime}$ & $\begin{array}{l}\text { apparent concrete strength } \\
\text { of column }\end{array}$ & $\varepsilon_{c y}$ & $\begin{array}{l}\text { strain in composite in } \\
\text { Y-direction }\end{array}$ \\
\hline$f_{c s}^{\prime}$ & $\begin{array}{l}\text { compressive strength of slab } \\
\text { concrete }\end{array}$ & $\varepsilon_{f y}$ & $\begin{array}{l}\text { strain in fiber in Y- } \\
\text { direction }\end{array}$ \\
\hline$f_{y}$ & $\begin{array}{l}\text { yield strength of deformed } \\
\text { bar }\end{array}$ & $\varepsilon_{m y}$ & $\begin{array}{l}\text { strain in matrix in Y- } \\
\text { direction }\end{array}$ \\
\hline$h$ & $\begin{array}{l}\text { thickness of slab column } \\
\text { joint }\end{array}$ & $L$ & \begin{tabular}{l} 
length of specimen \\
\hline
\end{tabular} \\
\hline
\end{tabular}

\section{REFERENCES}

[1] ACI Committee 363, "Report on High-Strength Concrete (ACI 363R10)", in: ACI Manual of Concrete Practice, American Concrete Institute, 2013

[2] ACI 318-14, Building Code Requirements for Structural Concrete and Commentary, American Concrete Institute, 2014

[3] A. C. Bianchini, R. E. Woods, C. E. Kesler, "Effect of Floor Concrete Strength on Column Strength," ACI Journal, Vol. 31, No. 11, pp. 11491169,1960

[4] J. K. Wight, Reinforced concrete : mechanics and design,Pearson, 2016

[5] M. K. Kayani, "Load Transfer from High-Strength Concrete Columns through Lower Strength Concrete Slabs", University of Illinois, 1992

[6] J. H. Lee, Y. S. Yoon, W. D. Cook, D. Mitchell, "Benefits of using puddled HSC with fibers in slabs to transmit HSC column loads", Journal of Structural Engineering, Vol. 133, No. 12, pp. 1843-1847, 2007

[7] S. C. Lee, P. Mendis, "Behavior of high-strength concrete corner columns intersected by weaker slabs with different thicknesses", ACI Structural Journal, Vol. 101, No. 1, pp. 11-18, 2004

[8] A. A. Shah, Y. Ribakov, "Estimation of RC slab-column joints effective strength using neural networks", Latin American Journal of Solids and Structures, Vol. 8, No. 4, pp. 393-411, 2011

[9] I. Shahid, S. H. Farooq, N. A. Qureshi, K. R. Kayani, H. Mumtaz, "Effective Concrete Strength within Slab- Column Joint", International Journal of Engineering and Technology Vol. 7, No. 3, pp. 965-972, 2015

[10] J.-H. Lee, Y.-S. Yoon, "Prediction of effective compressive strength of corner columns comprising weaker slab-column joint", Magazine of Concrete Research, Vol. 64, No. 12, pp. 1113-1121, 2012

[11] C.-C. Shu, N. M. Hawkins, "Behavior of Columns Continuous through Concrete Floors", ACI Structural Journal,Vol. 89, No. 4, pp. 405-414, 1993

[12] A. A. Shah, J. Dietz, N. V Tue, G. Koenig, "Experimental investigation of column-slab joints", ACI Structural Journal, Vol. 102, No. 1, pp. 103113,2005

[13] R. F. Gibson, Principles of composite material mechanics, McGraw-Hill, 1994

[14] P. J. McHarg, W. D. Cook, D. Mitchell, Y. S. Yoon, "Improved transmission of high-strength concrete column loads through normal strength concrete slabs", Structural Journal,Vol. 97, No. 1, pp. 157-165, 2000 